\title{
Which Ethics? Whose Morality?: An Analysis of Ethical Standards for Information Organization
}

\author{
Melodie J. Fox* and Austin Reece*** \\ *School of Information Studies, University of Wisconsin-Milwaukee, \\ PO Box 413, Milwaukee, WI 53201, USA <msjoblad@uwm.edu> \\ *:Department of Philosophy, Marquette University, PO Box 1881, \\ Milwaukee, WI 53201, USA < austin.reece@marquette.edu>
}

\begin{abstract}
Melodie J. Fox is a doctoral candidate at the University of Wisconsin-Milwaukee's School of Information Studies, where she also earned an MLIS, and is a member of the Information Organization Research Group. She also holds a Master's in English from the University of Illinois-Chicago. Her research interests include the relationship between epistemology and subject access, with a particular interest in the categorization of race and gender.
\end{abstract}

Austin Reece is currently a Ph.D. candidate in philosophy at Marquette University. He holds a Master's in contemporary European philosophy from University College Dublin and a Bachelor's in philosophy from Boston College. His research interests include philosophy of religion and ethics.

Fox, Melodie J. and Reece, Austin. Which Ethics? Whose Morality?: An Analysis of Ethical Standards for Information Organization. Knowledge Organization. 39(5), 377-383. 31 references.

ABSTRACT: Ethical standards are required at both the individual and system levels of the information organization enterprise, but are those standards the same? For example, are the ethical responsibilities of $D D C$ 's editorial board fundamentally the same as for an individual cataloger? And, what are the consequences of decisions made using different ethical frameworks to the users of knowledge organization systems? A selection of ethical theories suitable for evaluating moral dilemmas at all levels in information organization is presented, including utilitarianism, deontology, and pragmatism, as well as the more contemporary approaches of justice, feminist, and Derridean ethics. Finally, a selection of criteria is out-

lined, taken from the existing ethical frameworks, to use as a starting point for development of an ethical framework specifically for information organization.

Received 16 July 2012; Accepted 16 July 2012

\subsection{Ethics and information organization $(\mathrm{IO})$}

The creators of tools such as OPAC interfaces, classification systems, and thesauri that provide access to information, and those who apply those tools, such as catalogers and indexers, are all subject to ethical decision-making and consequently to ethical lapses, both intentional and unintentional. These lapses can result in harm to users, either through the inability to access
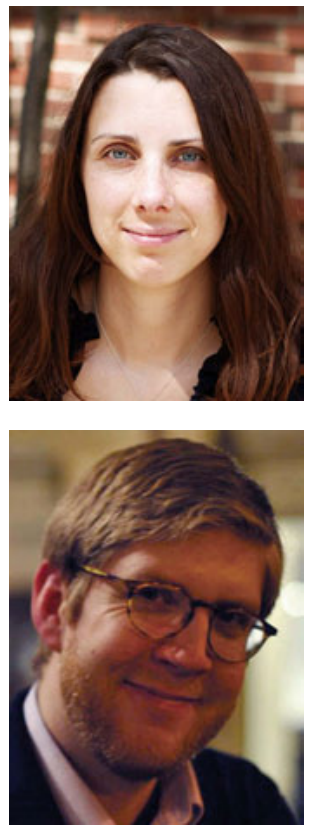

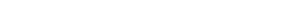


codes of ethics and ethical decision-making pertaining to access (Beghtol 2002, 2005; Jacobs 2007; Ferris 2008; Skekel 2008). Yet, most research on ethics in IO tends to rely on a premise of "ethicalness" not adhering to a particular philosophical framework, but rather a sense of right and wrong not rigorously defined. Beghtol $(2005,903)$, for example, admits that her steps in ethical decision-making "do not depend on the foundational assumptions of a particular school of ethical analysis or a particular ethical theory." Bair (2005), one of the few who does refer to ethical theories, suggests a code of ethics but focuses on catalogers only. In order to make ethical judgments, what is meant by "ethical" must be sufficiently defined, with the required criteria delineated to distinguish between better and worse practices within the field at all levels of the IO enterprise. If a reasonable set of ethical standards can be sketched out, then the only moral task remaining will be mainly interpretive, that is, applying the standards to the work to be done by systems-level vendors and classificationists as well as practitioners in the field.

\subsection{Epistemological assumptions}

The ultimate goal for IO is access, through means that do not oppress. Consequently, decisions in IO need to be examined through the application of ethics, or guidelines used to make reasoned judgments about questions of morality. Because of a changing epistemological landscape, classical and universalist epistemologies have suffered a critical beating. The evolution to postmodern thought holds profound consequences for classification, since the idea that no underlying truth exists undermines the bedrock of information organization (Miksa 1998). Likewise, the underlying epistemological assumption for this paper is skepticism of universal knowledge. A more detailed examination of the connection between epistemology and ethics offers an opportunity for further research, but is beyond the scope of this paper.

\subsection{Collective, system and individual}

In IO, the collective includes the entire enterprise, from catalogers, indexers, and other individual intermediaries, to the system level that includes classificationists, vendors, and bibliographic utilities. Systemslevel entities create and maintain structures to facilitate access and protect users from conceptual violence. A system such as OCLC or Library of Congress can be considered a "corporate person," which in turn has moral rights and responsibilities (Gerencser 2005). They provide tools and resources, but hold the greatest amount of agency because of size and power. A corporate person is ultimately a group of people who control a special medium of expression, i.e., certain individuals have a special, statecreated, stakeholder-funded mechanism for speaking more loudly than others, such as through classification systems. And, "more loudly" does not necessarily equate to "more truthfully" or "more ethically."

Individual intermediaries, such as catalogers and indexers, also work to maximize access and minimize harm. Since intermediaries simply apply preexisting standards, ethics are applied through cataloger's judgment and feedback methods such as requesting changes to classification systems. Ethical failures can also occur through errors (Bade 2002), personal agendas that lead to purposeful miscataloging, or naive trust in the system. Systems and individual catalogers generally have the same interests, but the imbalanced distribution of power and agency can lead to excesses and abuses of power at the expense of the weaker. Because of this imbalance, a singular ethical framework does not always hold the same consequences for user, cataloger, and system, and, at times, frameworks may conflict. This danger highlights the need for a sustained reflection on the appropriate ethical standards that protect all persons: both the individuals acting within the domain of corporate power and the corporate persons themselves.

\subsection{Existing ethical frameworks}

Examining traditional ethical frameworks can provide insight into these issues, but none are wholly sufficient. All ethical frameworks prescribe actions as we would like them to be practiced, but which often prove different than what occurs in reality. In this context, they offer methods to discern what actions ought to be done, as distinguished from studies that are primarily descriptive or examine real actions. Each framework below is presented in a necessarily reductive way, but addresses aspects relevant to IO. Examples are merely illustrative; many other situations apply. Though the chosen frameworks are, for the most part, traditional, western-centric ethics, in the interest of space and fairness of coverage, discussion of nonwestern frameworks such as Buddhist and African ethics have been saved for future research. 


\subsection{The utilitarian model}

For the utilitarian, only consequences matter in determining the moral worth of an action. The principle of utility makes up the sole criterion, which states that an action is right only insofar as it produces the greatest amount of happiness for the greatest amount of people (Mill 2001). Each individual's happiness is of equal worth: the same standards apply for collectives as for individuals, but actions should not be motivated by power or profit, only greater good for the collective. Goodness is usually understood as pleasure and the absence of pain with the belief that some pleasures are qualitatively superior to others.

J.S. Mill (2001) believed an experienced person, i.e., someone acquainted with both higher and lower pleasures, will recognize and prefer higher ones as more desirable. Thus, the judgment of the reflective person of experience becomes another criterion for demarcating right and wrong actions. In IO, goodness could be equated with the provision of access, which requires a master's degreed professional-an experienced person-to make decisions for the masses. Both systems and individual catalogers can serve as the experienced person, albeit in different capacities and with differing amounts of agency.

Despite the obvious value of an ethical model that promotes the welfare of all people, a serious limitation of utilitarianism is the justification of immoral means to maximize happiness. If an action serves the greater good and requires lying or killing, the action retains moral worth and could even be seen as mandatory in certain contexts. In the cases of say, $D D C$ 's 200 "Religion" class that focuses mainly on Christianity, or any of the XX9 "other" categories, if it could be shown that the highest amount of users benefit from those arrangements, they therefore support the principle of utility, which consequently should be permitted and even praised. The unquestioned acts of the "experienced person" perhaps are most evident in the dearth of user studies in IO (Hoffman 2009).

Despite the limitations, utilitarianism appears to be the ethical framework in action in IO, with standardization as the principal manifestation. The system creates KOS's that provide the greatest good for the dominant culture, and the cataloger can user cataloger's judgment or local policies to adapt that standard for its local audience. The question arises if, in the case of IO, the current system actually works for all users or if minority views and terminology become collateral damage to the greater good.

\subsection{Deontology: the Kantian model}

Kant's theory of ethics is deontological, meaning criterion for identifying right actions lies in something other than the consequences of the act itself. For Kant, an action is ethical if done from duty, which means following the categorical imperative (CI). The first version of the CI amounts to only acting on those personal rules that can be universalized for everyone. This provides a procedure for determining what actions are universally applicable and rationally consistent (Kant 1998). For example, a cataloguer might decide, that when he encounters a resource he finds personally offensive, he will deliberately misclassify it. What Kant's model requires of the cataloguer is an imaginative act where the subjective rule is envisioned as a moral law for everyone, which would mean rephrasing it to say, "all people should hide books from others when they find them personally offensive." If one can envision this without contradiction, then the act is permissible. Kant's point is that to want something (that one's views not be challenged) and its opposite (that one's views be challenged) at the same time is contradictory and irrational, and thus intrinsically bad.

Limitations to Kant's model include the insistence on exceptionless rules and reliance on individuals to choose what is best, given people's limited imaginations, the complexity of any given situation, and the difficulty of resolving conflicts of duty. The most ominous limitation in a service-oriented field is that if bad things happen as a result of your dutiful actions, you are blameless. This suggests that at the system or individual level, to try is enough. As long as the effort was put forth by convening committees of experts and making some attempt, there would be no need to test the efforts through user studies or be concerned if the ultimate goal of access remains unattained.

\subsection{The Rawlsian model: justice ethics}

For John Rawls, the central question of ethics is deciding what is just. More concretely, he is concerned with how goods, such as access to information, ought to be distributed in society. Like Kant, his axiomatic starting point is that people are rational, autonomous and free, which means they are dignified beings worthy of respect and equal treatment. His method for generating principles that will preserve the dignity of persons and minimize injustice is expressed through a hypothetical social contract called the "original position" (2005). To insure impartiality and fairness to all 
members of the social contract, the original position is imagined under a "veil of ignorance" where certain limits are placed on the subjects' self-knowledge, e.g., race, gender, economic class, and natural abilities. Ideally, this veil of ignorance will act as a safeguard against the arbitrary manipulation of social structures by one group over and against another. The attempt to remove prejudice ostensibly places the disadvantaged on a level plane. However, this approach can ignore past injustices to marginalized groups.

Given the limits of the original position and the human desire to further self-interest, this fictional thought experiment asks members to adopt two principles of justice, namely, the principle of equal liberty and the principle of difference. The principle of equal liberty seeks to maximize the level of individual liberty that is roughly equal to the liberty of all others. The principle of difference seeks to establish an appropriate distribution of wealth where some inequalities are tolerated only if they benefit the worst off in society. Rawlsian justice also assumes decisions will be made in a "reasonable" unself-interested way and can bear the "burden of judgment," which means it would be able to be justified (Rawls 1996). Another stipulation is that if an end is willed, so must be the means to achieve it, so if a change or rule is mandated, it necessarily must be accompanied by resources and tools for implementation.

The American Library Association (ALA's) (2008) Code of Ethics and Core Values of Librarianship exemplify Rawls's conception of justice. The first principle of the Code of Ethics requires "equitable service policies; equitable access; and accurate, unbiased, and courteous responses to all requests." The emphasis on "equitable" indicates distributive justice, and "unbiased" assumes a type of original position. The Core Values (2004) defines equity of access to mean "that all people have the information they need-regardless of age, education, ethnicity, language, income, physical limitations or geographic barriers...It also means they are free to exercise their right to know without fear of censorship or reprisal," again, a veil of ignorance.

Abiding by Rawlsian justice means that, similarly to Kantian deontology, a normative sense of neutrality would govern the domain through standards. Ethical dilemmas are not viewed in context, but rather only in light of the norms of the domain. Therefore, no need exists to consider each individual's situation: normativity would determine under what rules the decision would abide, and any differentiating details would be erased from the decisionmaking process. The systems and rules remain, and users must adapt to them, rather than the other way around. The catalogers' need to make decisions is removed as they would be directed to follow standards, which have been determined as the universal for the domain. When exercising cataloger's judgment, the veil of ignorance removes contextual disadvantage. Therefore, if bias is desired, such as through localized records, it cannot be done.

\subsection{Feminist ethics: ethic of care}

The ethic of care framework arose as a feminist response by Carol Gilligan (1982) to Lawrence Kohlberg's interpretation of justice ethics, which she found to be based on sexist studies that favored strict rationality. Despite its feminist origins, it has since been interpreted as gender-neutral (Tronto 1987). "Care" does not imply affection or loving emotion, but rather is a strategy that values collaboration, relationships, and context in ethical decision-making. Rather than decontextualizing moral dilemmas, a care framework views dilemmas in their specific contexts and accommodates exceptions. Unlike the infallible rules of a justice ethic, rules are bendable, and the decision maker must consider the needs of each individual and work collaboratively to find the best solution to preserve the relationship between institution, service-provider, and user.

The reference interview demonstrates use of the ethic of care in a library setting, but can it be recreated in an environment governed by authority control? Standardization at a system level would be difficult if using the ethic of care, since it tends to be relativistic; however, it aligns with the current paradigm in IO research in that it seeks creative ways to accommodate context for users while still maintaining bibliographic control. For an individual cataloger, it would be time consuming if not impossible to consider or know all factors of each individual user who might possibly search for the resource; however, with some reasonable limitations, the results would be localized records or other innovations that could seek out contextual information at the local level.

\subsection{Derridean ethics}

For Derrida, "the Other" is a singular existent having an inalienable mode of being that can never be repeated (Derrida and Dufourmantelle 2000; Derrida 2004). Derrida envisions a "right to difference" that would allow the other to remain other and not be reduced to the "same" by any totalizing system. Thus, 
an ethical subject must be committed to an ideal of unconditional hospitality for all others, which can never be fully realized. Every "Other" is welcome across the threshold into the system or category. But this involves a perpetual risk, as everyone is a potential threat or menace, as hospitality can lead to hostility, so, in reality, limits are always set on who is welcome. Every time a constraint is put in place, a door closes for someone; the goal of Derridean ethics is to keep borders porous.

KOS's governed by a Derridean ethical framework would be hospitable to the extreme, where any and all viewpoints or terminology would be welcome. What Derrida would call "violence" would occur at the border of categories-if borders exist-resulting in little to no categorical stability. Therefore, the system would not be much more than a loose structure that houses unregulated subject and descriptive terms, much like a social tagging environment. Similarly to tagging, intermediaries such as catalogers would be seen as door-closing constraints, rendering them unnecessary. For the user, however, Derridean ethics offer the greatest amount of agency. Users are exposed to a wider selection of terminology and viewpoints, sometimes conflicting and sometimes distasteful, but the trust falls to the user to judge what fulfills the information need.

\subsection{Pragmatic ethics of John Dewey}

For the pragmatist, efficacy of action is the sole criterion for determining rightness. Like the hard sciences, pragmatism stresses the need for observable results, predictive success, and revising current practices in light of new experiential evidence. "Concrete reasonableness," the ideal for rightness, is that which makes the world more intelligible, controllable, and orderly (Serra 2009). Serious deliberation is required of a moral agent to test which actions are more likely to conform to this ideal. The agent must imagine various acts and their consequences, being careful to think through all the logical possibilities that pertain to the context of the act. This testing should be done with the help of the "community," however defined. A special concern also exists for inculcating habits that make living the moral life sustainable, e.g., critical thinking, empathetic imagination, and experimentation. For Dewey, education was revered as a primary tool for the development of moral habits (Dewey 1983).

Naturally, pragmatic ethics resemble pragmatic epistemology as imagined by Hjørland and Hartel (2003) in domain analysis. Pragmatists also believe that no one comprehensive view of reality or set of theories and laws exists and that no philosophical inquiry can be separated from day-to-day life. Because of the lack of universal reality, meaning is unstable and created socially. Pragmatism requires that concepts are developed in relation to a particular need or task. Concepts would be defined by domain's "community" and would ethically require continual revision and empirical validation through user studies to ensure utmost accuracy. The cataloger's decisions are solitary acts, but must be socially verified to ensure they are consistent with the ideal of concrete reasonableness. When using cataloger's judgment, they must play out the possible consequences to the user before acting, similarly to how Christensen (2011) recommends a classificatory position for the term "intersex." The decision would then be followed up by a user study. Ultimately, for the user, system and intermediary, actions result in better efficacy of KOS's.

\subsection{Our model}

In an attempt to glean the best features from major ethical theories while circumnavigating some of the obvious weaknesses in any one of them taken individually, we have outlined a selection of criteria to use as a starting point for development of an ethical framework specifically for information organization, applicable to both individual and corporate persons:

- A duty to care: Miller (2005) uses Kant's Principle of Beneficence combined with the ethic of care to illustrate how a binding sense of duty exists to help others in need. She writes that all humans have potential for vulnerability and interdependency, so care can be an integral part of the categorical imperative. A duty to care would involve imaginative, empathetic application of standards through cataloger's judgment and an obligation to cater to context to preserve agency.

- Hospitable, with mitigation: Derridean hospitality in itself would render the system unusable, so with some vigilance for harm, hospitality could be combined with a more restrictive system. For example, tags could be used in tandem with controlled vocabularies (Kipp and Campbell, 2010). Also, an ideal of unconditional hospitality would be a perpetual counterbalance to practices relying on invasive surveillance and (bibliographic) control as outlined in Foucault's work $(1994,1995)$.

- Consequence-driven, emphasizing improvement of practice: In a practical setting like IO, results 
matter, and a functioning system that promotes user satisfaction is a priority. Thus, consequences of justice, care, hospitality, practical efficacy, and so forth must be regularly monitored and maintained through iterative feedback and testing mechanisms.

- Treats people as ends with basic rights and responsibilities: Regardless of whether a theoretical foundation for rights can ever be established, the practical necessity to take rights seriously stems from the historical realities of discrimination and genocide and forms of conceptual violence that support such atrocities.

- Prescribes no action we are certain is wrong: This prevents overt offenses such as the use of terminology like "idiots asylums" for homes for the mentally ill, as in historical versions of Library of Congress Subject Headings. It also prevents the deliberate misapplying of standards to inhibit access.

\subsection{Conclusion}

Budd $(2006,257)$ reminds us, "If there are conflicts and contests among ... forces, we as professionals have to address them;" thus, an ethical model for IO must address conflicts of duty, such as those between systems and individuals. No diffusion of responsibility should occur, but rather all persons acting in the collective must be committed to a shared, living conception of goodness, which, in the case of IO, is access without harm. Researchers both as theorists and practitioners have recognized the moral tasks at hand and work toward solutions. However, because of the inability to directly affect outcomes, researchers can work in a Kantian framework where the work is done out of internal morality but may be inconsequential. But nonetheless, all of the collective must work to attain the end of benevolent user access, which should be the shared axiomatic starting point of any ethical model of IO.

\section{References}

American Library Association. 2004. "Core values of librarianship.” Available http://www.ala.org/ala/ aboutala/offices/oif/statementspols/corevaluesstate ment/corevalues.cfm\#social.

American Library Association. 2008. "Code of ethics of the American Library Association." Available http://www.ala.org/advocacy/proethics/codeofethi cs/codeethics.
Bade, David. 2002. The creation and persistence of misinformation in shared library catalogs: language and subject knowledge in a technological era. UrbanaChampaign, Ill.: University of Illinois.

Bair, Sheila. 2005. Toward a code of ethics for cataloging. Technical services quarterly 23n1: 13-26.

Beghtol, Clare. 2002. A proposed ethical warrant for global knowledge representation and organization systems. Journal of documentation 58: 507-32.

Beghtol, Clare. 2005. Ethical decision-making for knowledge representation and organization systems for global use. Journal of the American Society for Information Science and Technology 56: 903-12.

Budd, John M. 2006. Toward a practical and normative ethics for librarianship. The library quarterly 76: 251-69.

Christensen, Ben. 2011. Interfiling intersex: how Dewey classifies intersex in theory and practice. In Greedblatt, Ellen ed., Serving LGBTIQ library and archive users: essays on outreach, services, collections and access. Jefferson, NC: MacFarland, pp. 201-11.

Derrida, Jacques. 2004. Deconstruction and the other. In Kearney, Richard ed., Debates in continental philosophy: conversations with contemporary thinkers. New York: Fordham University Press, pp. 3-14.

Derrida, Jacques, and Dufourmantelle, Anne. 2000. Of hospitality. Translated by Rachel Bowlby. Stanford, Calif.: Stanford University Press.

Dewey, John. 1983. 1899-1924: the middle works. 14 volumes. Edited by Jo Ann Boydston. Carbondale: Southern Illinois University Press.

Ferris, Anna M. 2008. The ethics and integrity of cataloging. Journal of library administration 47n3/4: 173-90.

Foucault, Michel. 1994. The order of things: an archeology of the buman sciences. New York: Vintage.

Foucault, Michel. 1995. Discipline and punish: the birth of the prison. New York: Vintage.

Gilligan, Carol. 1982. In a different voice: psychological theory and women's development. Cambridge, Mass.: Harvard University Press.

Gilligan, Carol. 1986. Forum: different voice: reply by Carol Gilligan. Signs: journal of women in culture and society 11: 324-33.

Gerencser, Steven. 2005. The corporate person and democratic politics. Political research quarterly 58: 625-35.

Hjørland, Birger, and Hartel, Jenna. 2003. Afterward: ontological, epistemological and sociological dimensions of domains. Knowledge organization 30: 239-45. 
Hoffman, Gretchen L. 2009. Meeting users' needs in cataloging: what is the right thing to do? Cataloging E classification quarterly 47: 631-41.

Jacobs, Christine. 2007. Ethical places, ethical spaces: stopping to listen. The indexer 25: 161-66.

Kant, Immanuel. 1998. Groundwork of the metaphysics of morals. Edited by Mary Gregor, translated by Christine M. Korsgaard. New York: Cambridge University Press.

Kipp, Margaret E.I., and Campbell, D. Grant. 2010. Searching with tags: do tags help users find things? Knowledge organization 37: 239-55.

Miksa, Francis L. 1998. The DDC, the universe of knowledge, and the post-modern library. Albany, NY: Forest Press.

Mill, John Stuart. 2001. Utilitarianism. $2^{\text {nd }}$ Ed. Indianapolis, Ind.: Hackett.

Miller, Sarah C. 2005. A Kantian ethic of care? In Andrew, Barbara, Keller, Jean, and Schwartzman, Lisa eds., Feminist interventions in ethics and Politics: feminist ethics and social theory. Lanham, MD: Rowman \& Littlefield, pp. 111-27.

Olson, Hope A., and Schlegl, Rose. 2001. Standardization, objectivity, and user focus: a meta-analysis of subject access critiques. Cataloging $\mathcal{E}$ classification quarterly 32n2: 61-80.

Rawls, John. 1996. Political liberalism. New York: Columbia University Press.

Rawls, John. 2005. A theory of justice: original edition. Cambridge, Mass.: Belknap.

Serra, Juan Pablo. 2010. What is and what should pragmatic ethics be?: some remarks on recent scholarship. European journal of pragmatism and American philosophy 2n2:100-14.

Skekel, Donna. 2008. Ethical, unethical, or benign: technical services decisions and access to information. Journal of information ethics 17n1: 20-27.

Tronto, Joan C. 1987. Beyond gender difference to a theory of care. Signs: journal of women in culture and society 12: 644-63. 